\title{
APPLICATION OF RESPONSE SURFACE METHODOLOGY FOR THE OPTIMIZATION OF BIODIESEL PRODUCTION VIA TRANSESTER- IFICATION OF CASTOR OIL WITH CALCIUM OXIDE
}

\author{
Musa Idris Atadashi ${ }^{1}$ (10) and Thomas Akummadzna Darius ${ }^{1}$ \\ ${ }^{1}$ Department of Chemistry, Faculty of Science, Adamawa State University, Mubi, Nigeria
}
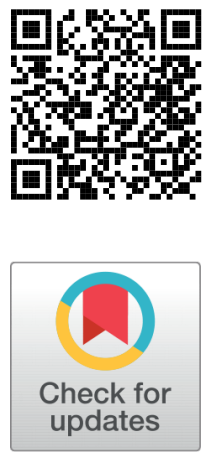

Received 8 March 2021

Accepted 10 April 2021

Published 30 April 2021

Corresponding Author

Musa Idris Atadashi, atadashimus

a1@yahoo.com

DOI $10.29121 /$

granthaalayah.v9.i4.2021.3774

Funding: This research received no specific grant from any funding agency in the public, commercial, or not-for-profit sectors.

Copyright: (C) 2021 The Author(s). This is an open access article distributed under the terms of the Creative Commons Attribution License, which permits unrestricted use, distribution, and reproduction in any medium, provided the original author and source are credited.

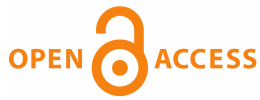

\section{ABSTRACT}

Castor seeds were processed and the oil was extracted from the paste by cold pressing and the yield obtained was $42.80 \%$. Moisture content of $4.38 \%$ was found. The crude oil was obtained as clear, viscous, pale-yellow liquid. Transesterification of crude castor oil with methanol to produce biodiesel in the presence of calcium oxide $(\mathrm{CaO})$ as a catalyst was carried out. This study analysed the fuel properties of biodiesel; the FTIR spectrum for the biodiesel revealed the functional groups with characteristics bands, $\mathrm{C}=\mathrm{O},-(\mathrm{CH} 2) \mathrm{n}-, \mathrm{C}-\mathrm{O}, \mathrm{C}=\mathrm{C}, \mathrm{OH}$ and $\mathrm{C}-\mathrm{H}$ in the spectrum. From the result of the FTIR and GC-MS, the methyl ester groups present in the biodiesel produced was determined and 9-Octadecenoic acid-12-hydroxy- methyl ester was identified as the most abundant compound in the biodiesel which have all the functional groups as revealed by the FTIR. The experimental design as well as statistical analysis were done and analysed using Response Surface Methodology (RSM) design expert 12.0 version software which was also used for the optimization of the three process parameters. The optimum conditions for biodiesel production were a reaction temperature of $62^{\circ} \mathrm{C}$, methanol to oil ratio of $11: 1$ and a catalyst of $3.5 \mathrm{wt} \%$ of oil at 1 hour. The biodiesel content under these optimum conditions was $54 \%$. $\mathrm{R}^{2}$ value of 0.9996 was obtained showing good fitting.

Keywords: Coconut Oil, Sodium Hydroxide, Transesterification, Biodiesel, Purification

\section{INTRODUCTION}

Energy is the prime mover for economic development. Depletion of fossil reserves increases interest to search for alternative fuel, which have same properties as diesel, to replace such fossil fuel (Andrijanto (2012) ). Among the renewable energy sources, biodiesel is ranked the best alternative to diesel fuel (Zavarize et al. (2021) ). Biodiesel has been defined as a mono-alkyl ester of vegetable oils or animal 
fats. Biodiesel is best substitute for petro-diesel and also most advantageous over petro-diesel for its environmental friendliness (Andrijanto (2012) ). With the aim of developing a process of biodiesel production that is environmentally benign much interest has been focused on the use of solid base catalysts, such as calcium oxide, for the transesterification of vegetable oils with methanol (Arzamendi et al. (2007) ).It has very similar physical properties to diesel fuel and even higher cetane number which allows it to be used directly as substitute fuel for diesel engines without any modifications or as a blending agent for diesel fuel. Since it is produced from renewable and domestically grown feed-stocks, it can reduce the demand for petroleum based fuels and possibly lower the overall cost of diesel fuel (Nahadi and IM (2018) ).

The chemical process used to obtain biodiesel is based on the solid in the system catalyzing the reaction to reduce the time and the cost of the process through the reuse of the catalyst, decreasing the level of impurities in the reaction products (Nahadi and IM (2018) ). Biodiesel due to its agricultural source essentially contains no or very little sulfur and thus offers promise to reduce particulate and toxic emissions, which is one of the primary objections to diesel engine (Musa (2016) ). One of such oils is castor oil that is obtained from castor plant RicinusCommuniswhich belongs to the family of Euphorbiaceae. The beans contain $35-55 \%$ oil by weight for high yield breed type; it has higher viscosities among vegetable oils and a molecular weight of 298. It is hard non-drying oil that neither becomes stiff with cold nor unduly thin with heat hence it is used as a lubricant for jet and racing cars engines. It is the only source of an 18-carbon hydroxylated fatty acid with one double bond in each of the fatty acid chain and ricinoleic acid make up over $87 \%$ of the fatty acid composition (Atapour and Kariminia (2011) ). The presence of a hydroxyl group at C12 of the ricinoleic acid, the ester linkages, double bonds and hydroxyl groups provide reaction sites that makes it unusually polar which provides sites for the production of a wide range of natural and synthetic resins, waxes, polymers and elastomers. It also has excellent emollient and lubricating properties, a marked ability to wet and disperse dyes, pigments and fillers and as well as several medicinal values (Balat and Balat (2008) ). Castor oil has excellent solubility in alcohols, for this reason it is theoretically ideal oil for transesterification to biodiesel, requiring a minimum amount of catalyst and heating which can reduce costs of production (Chew and Bhatia (2008) ). The homogeneous catalyzed transesterification of vegetable oil for biodiesel production have some drawbacks such as saponification of the oil, unable to recover catalyst, and limitation in establishing a continuous process and therefore reducing biodiesel yield (Chukwueyem et al. (2015) ). In contrast, the solid catalysts could easily be separated from the reaction mixture by filtration and reused. Among the heterogeneous catalysts, calcium oxide has derived researcher's attention because it is a cheap and abundantly available in the nature. Calcium oxide can be reused up to 3 times in transesterification reaction which made it an economic catalyst (Nahadi and IM (2018) ). As the calcium oxide is derived from the natural source, it is envi- 
ronmentally friendly and causes no harm to the ecosystem (Chew and Bhatia (2008) ).

Environmental concerns have also led to the search for solid catalysts which are eco-friendly and effective (Atapour and Kariminia (2011) ). The transesterification reaction proceeds with catalyst or without any catalyst by using primary or secondary monohydric aliphatic alcohols having 1-8 carbon atoms. Among the alcohols that can be used in the transesterification reaction are methanol, ethanol, propanol, butanol and amyl alcohol. Methanol and ethanol are used most frequently. A successful transesterification reaction produces two liquid phases: ester and crude glycerol (Chung et al. (2008) ).

Application of heterogeneous catalysts in the field of renewable energy to produce renewable fuel has become a significant area of research due to environmental concerns resulting in continual dependence on finite fossil fuel sources, current industrial energy demands and upswing in the world population. To this end, current research is focused on fuel derivable from renewable sources using heterogeneous catalyst and its utilization in the transportation industries and other industrial processes.

Catalytic reactions are known to go faster to completion whether homogeneous or heterogeneous. However, usage of homogeneous catalyst is characterized by cumbersome process and high cost of product vis-a-vis environmental pollution (Demirbas (2008) ). Therefore, in this research work castor oil was chosen for the production because it has excellent solubility in alcohols.

\section{MATERIALS AND METHODS}

\subsection{MATERIALS}

Crude Castor oil was extracted from castor seed, methanol, 99.8\% purity (analytical grade), and Calcium oxide ( $\mathrm{CaO}$ ) were purchased.

\subsection{EXPERIMENTAL DESIGN}

The experimental design was carried out using Response Surface Methodology (RSM) design expert 12.0 version software as presented in Table 1

\subsection{TRANSESTERIFICATION PROCESS FOR THE PRODUCTION OF BIODIESEL}

The transesterification process was carried out using a batch reactor. A stirrer was used to stir the mixture in the screw-capped vessel. The vessel was kept in a water bath to maintain the temperature. The mixture was stirred at a speed of $300 \mathrm{rpm}$ for all test runs. After the transesterification reaction, the product mixture was poured into a beaker and then allowed to settle into two phases. Since methanol has boiling point of $64.7^{\circ} \mathrm{C}$ higher reaction temperature of $62^{\circ} \mathrm{C}$ was used (Farahmandjou and 
Golabiyan (2016) ). As per stoichiometry reaction carried out at 6:1 to $16: 1$ methanol to oil molar ratio and a catalyst concentration of $1 w / w \%$ to $6 w / w \%$. Further by keeping required time constant, the mixture of methanol, and calcium oxide solution was added into the batch reactor. Further the reaction time was 60 min for all experimental runs.

Table 1 Process Parameters for the Production of Biodiesel

\begin{tabular}{cccc}
\hline Run & $\begin{array}{c}\text { Factor 1. A: Cat. Con. } \\
\text { w/w\% }\end{array}$ & $\begin{array}{c}\text { Factor 2 B: Molar } \\
\text { ratio }\end{array}$ & $\begin{array}{c}\text { Factor3C: Temperature } \\
{ }^{\circ} \mathbf{C}\end{array}$ \\
1 & 6 & 16 & 50 \\
2 & 3.5 & 6 & 56 \\
3 & 6 & 6 & 62 \\
4 & 3.5 & 11 & 56 \\
5 & 3.5 & 11 & 50 \\
6 & 3.5 & 16 & 56 \\
7 & 6 & 16 & 62 \\
\hline 8 & 3.5 & 11 & 56 \\
9 & 3.5 & 11 & 56 \\
10 & 1 & 11 & 56 \\
\hline 11 & 1 & 6 & 50 \\
12 & 1 & 16 & 50 \\
13 & 3.5 & 11 & 56 \\
14 & 3.5 & 11 & 56 \\
15 & 3.5 & 11 & 62 \\
16 & 6 & 11 & 56 \\
\hline 17 & 1 & 6 & 62 \\
18 & 6 & 6 & 50 \\
\hline 19 & 1 & 16 & 62 \\
\hline 20 & 3.5 & 11 & 56 \\
\hline
\end{tabular}

\subsection{PURIFICATION OF CRUDE BIODIESEL PRODUCED}

After the transesterification is completed, in the end, the excess methanol was distilled off under vacuum. The product was centrifuged, and three phases were formed, the upper layer was biodiesel, the middle layer was glycerol, and the lower layer was a mixture of solid $\mathrm{CaO}$ and a small amount of glycerol. The biodiesel was collected for chromatographic analysis (Freedman et al. (1984) ). The phase separation between biodiesel and catalyst was characteristically clean and absolutely complete (Fukuda et al. (2001) ). The upper layer, containing the refined biodiesel product, was then stored and prepared for analysis.

\subsection{ANALYSIS OF THE BIODIESEL PHASE}

The ethyl ester compounds in biodiesel samples was analyzed by a HP 6890 Gas Chromatogram (GC) equipped with a Flame Ionization Detector (FID) and capillary col- 
umn DB23 (60-m $\times 0.25-\mathrm{m} \times 0.15-\mu \mathrm{m})$ according to a methodology proposed by Agilent. Normal hexane solutions of the biodiesel samples with a concentration of 100 $\mathrm{mg} / \mathrm{ml}$ was injected by an auto injector at an oven temperature of $50{ }^{\circ} \mathrm{C}$, which was heated up to $230{ }^{\circ} \mathrm{C}$. The injector temperature and the detector temperature were $250^{\circ} \mathrm{C}$ and $280^{\circ} \mathrm{C}$, respectively; helium was used as the carrier gas (Demirbas (2008) ).

\subsection{GAS CHROMATOGRAPHY- MASS SPECTROSCOPY (GC-MS)}

The biodiesel product was analyzed by Fourier Transform Infra-Red spectrometer (Nicolet 5700) and Gas Chromatography-Mass Spectrometry. The fatty acid methyl esters (FAMEs) in the produced biodiesel were then characterized and identified using gas chromatography-mass spectrometry fitted with $5 \mathrm{MS}$ column $(30 \mathrm{~m}$, $0.25 \mathrm{mmID}, 0.25 \mu \mathrm{m})$. GC-MS analysis mainly identifies the quality and quantity of the produced biodiesel resembled in the methyl esters present in the crude castor oil sample. This technique also gives the distribution area for each component in the produced sample. The total yield of the biodiesel was finally calculated.

\subsection{FOURIER TRANSFORM INFRARED SPECTROSCOPY (FT-IR)}

Fourier transform infrared spectroscopy was used to determine the main functional group presence in the produced biodiesel and its castor oil. The IR spectrum was scanned through a wavelength range of $4000-400 \mathrm{~cm}^{-1}$. The FT-IR technique was used for quantitative and qualitative analysis of the produced biodiesel and to confirm GC-MS results.

\section{RESULTS AND DISCUSSIONS}

\subsection{BIODIESEL YIELDS}

The yields of biodiesel obtained using twenty experimental runs were shown in Table 2 . It is worthy to mention that highest biodiesel of $54 \%$ was obtained in the run 4 and 13 during the transesterification reaction, and the lowest yield of $23 \%$ swas recorded in the run 3 , as shown in Table 2 . The process parameters considered in this study include amongst others, the molar ratio of oil to methanol, catalyst concentration, and reaction temperature. From Table 2 , the molar ratio of methanol to oil has a significant impact on the biodiesel yield. Thus, $54 \%$ yield was reported at 11:1 molar ratio of oil to methanol. The excess methanol was necessary because it increased the rate of methanolysis. The higher amount of methanol promoted the formation of methoxy species on the $\mathrm{CaO}$ surface, leading to a shift in the equilibrium towards forward direction, thus increasing the rate of biodiesel conversion (Gomes et al. (2010) ). However, the yield was slightly reduced when the ratio of oil to methanol was higher than 11:1, this is due to excessive methanol above the optimal point. 
Catalyst concentration played an important role during the transesterification reaction. From Table 2 , it was seen that biodiesel yield increase with increased catalyst concentration ranging from $1 \% \mathrm{w} / \mathrm{w}$ to $6 \% \mathrm{w} / \mathrm{w}$. Thus catalyst concentration of $3.5 \% \mathrm{w} / \mathrm{w}$ of $\mathrm{CaO}$ provided highest biodiesel yield of 54\%. Furthermore, Table 2 , showed the significance of reaction temperature during castor oil transesterification to biodiesel fuel. The biodiesel yields obtained were determined at different reaction temperature ranging from 50 to $62{ }^{\circ} \mathrm{C}$. The biodiesel yield increased with the increased in reaction temperature until an optimal point of $56^{\circ} \mathrm{C}$, with biodiesel yield of $54 \%$. Above this optimum temperature, the yield was decreased. High temperature are not preferred; as the temperature increases and approaches boiling point of methanol, the methanol quickly vaporizes and form a large number of bubbles and thus decreased the yield of biodiesel (Gui et al. (2008) ).

Table 2 Biodiesel Yields

\begin{tabular}{cccccc}
\hline Std & Run & $\begin{array}{c}\text { Factor 1 A: Cat. Con } \\
\text { w/w\% }\end{array}$ & $\begin{array}{c}\text { Factor 2 B: } \\
\text { Molar ratio }\end{array}$ & $\begin{array}{c}\text { Factor 3 C: } \\
\text { Temp }\end{array}$ & $\begin{array}{c}\text { Biodiesel Yield } \\
\text { \% }\end{array}$ \\
\hline 4 & 1 & 6 & 16 & 50 & 40.50 \\
11 & 2 & 3.5 & 6 & 56 & 42.80 \\
\hline 6 & 3 & 6 & 6 & 62 & 23.00 \\
\hline 19 & 4 & 3.5 & 11 & 56 & 54.00 \\
13 & 5 & 3.5 & 11 & 50 & 52.60 \\
\hline 12 & 6 & 3.5 & 16 & 56 & 53.00 \\
\hline 8 & 7 & 6 & 16 & 62 & 42.00 \\
\hline 16 & 8 & 3.5 & 11 & 56 & 52.40 \\
\hline 20 & 9 & 3.5 & 11 & 56 & 53.30 \\
\hline 9 & 10 & 1 & 11 & 56 & 33.00 \\
\hline 1 & 11 & 1 & 6 & 50 & 31.50 \\
\hline 3 & 12 & 1 & 16 & 50 & 27.60 \\
\hline 17 & 13 & 3.5 & 11 & 56 & 54.00 \\
\hline 18 & 14 & 3.5 & 11 & 56 & 52.70 \\
\hline 14 & 15 & 3.5 & 11 & 62 & 52.80 \\
\hline 10 & 16 & 6 & 11 & 56 & 37.00 \\
\hline 5 & 17 & 1 & 6 & 62 & 31.50 \\
\hline 2 & 18 & 6 & 6 & 50 & 23.10 \\
\hline 7 & 19 & 1 & 11 & 62 & 29.00 \\
\hline 15 & 20 & 3.5 & & 56 & 53.20 \\
\hline
\end{tabular}

\subsection{CHARACTERISTIC BAND POSITIONS FOR BIODIESEL}

FromTable 3 it is worth noting that the characteristics peaks found in the region $1169.82 \mathrm{~cm}^{-1}$ indicated stretching vibrations of $\mathrm{C}-\mathrm{O}$ and $\mathrm{C}-\mathrm{O}-\mathrm{C}$. They can also indicate the bending vibration of $0-\mathrm{CH}_{3}$ in the spectrum (12). The band region of $1461.82 \mathrm{~cm}^{-1}$ can be ascribed to the bending vibration of $\mathrm{C}-\mathrm{H}$ methyl groups in the fuel. The characteristics peak at wave number $1739.96 \mathrm{~cm}^{-1}$ which is the strongest in the spectrum is attributed to $\mathrm{C}=0$ groups with the stretching mode of vibration. 
These groups indicated the presence of carbonyl functional groups in the biodiesel. The groups indicated the conversion of triglycerides in the oil to methyl esters (biodiesel) (13). The peaks at $2862.15 \mathrm{~cm}^{-1}$ and $2932.39 \mathrm{~cm}^{-1}$ indicated symmetric and asymmetric stretching vibrations of $\mathrm{C}-\mathrm{H}$ alkane groups respectively. They could be methyl $\left(\mathrm{CH}_{3}\right)$ or methylene groups in the esters chains of the biodiesel and they require high energy to cause stretching vibrations within their bond when compared to the ordinary $\mathrm{C}-\mathrm{H}$ bending vibrations of alkene groups detected at low energy and frequency region (14). The peak at $3014.44 \mathrm{~cm}^{-1}$ is attributed to the stretching vibration of $=\mathrm{C}-\mathrm{H}$ alkene groups. They are detected above wave number $3000 \mathrm{~cm}-1$ in the spectrum compared to corresponding alkane $\mathrm{C}-\mathrm{H}$ stretching groups detected below $3000 \mathrm{~cm}^{-1}$. However, biodiesel showed oxygen functional group of ester $\mathrm{C}-\mathrm{O}$ bond at $1104.67 \mathrm{~cm}^{-1}$ to $1175.96 \mathrm{~cm}^{-1}$ and ester $\mathrm{C}=0$ bond at $1739.96 \mathrm{~cm}^{-1}$. The presence of oxygen in biodiesel promotes cleaner and complete combustion. On the other hand, the conventional diesel with less oxygen component produced more black smoke and incomplete combustion during burning (12). From the result of GC-MS, it was possible for one to determine the methyl ester groups present in the biodiesel produced. 9-Octadecenoic acid-12-hydroxy- methyl ester was identified from Table 2 . It was found to be the most abundant compound.

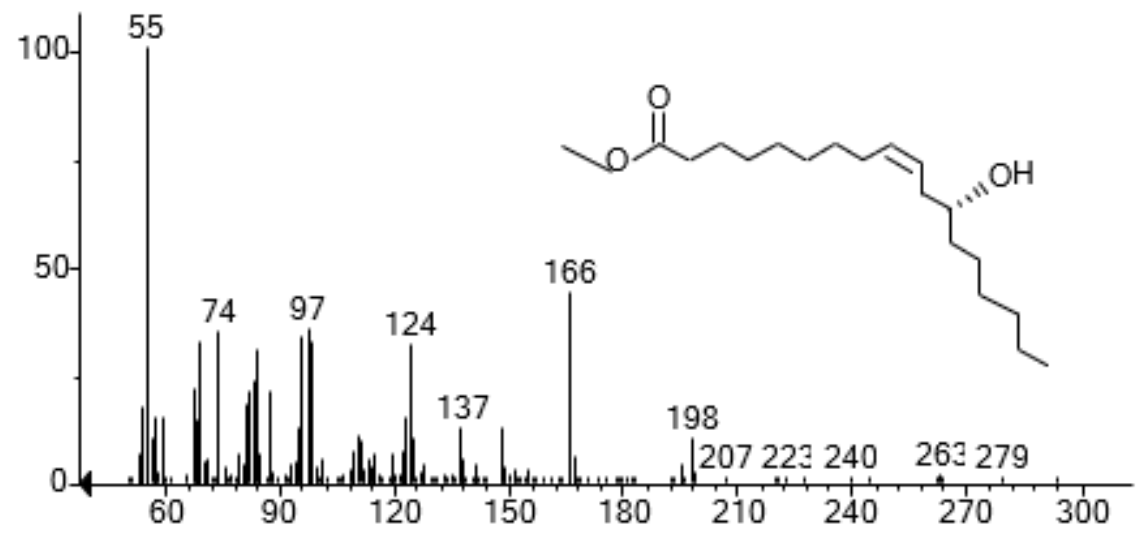

Figure 1 Structure of the 9-Octadecenoic acid, 12-hydroxy-, methyl ester from GC-MS.Other names: Methyl ricinoleate; Ricinoleic acid methyl ester; Flexricin P-1; Methyl ricinolate; 12-Hydroxy-9octadecenoic acid methyl ester.

\subsection{OPTIMIZATION OF BIODIESEL PRODUCTION USING RESPONSE SURFACE METHODOLOGY}

The selected independent reaction parameters (reaction temperature, methanol to oil molar ratio and catalyst concentration) were optimized using design of experiment software (version 12.0). Response surface method (RSM) provides elaborate analysis of reaction parameters on the production process. In order to optimize the process parameters, a twenty designed experiments were conducted and analyzed 
Table 3 FT-IR Characteristic Band Positions for Castor oil and Castor oil Biodiesel

\begin{tabular}{cccc}
\hline $\begin{array}{c}\text { Castor oil } \\
\begin{array}{c}\text { Characterization } \\
\text { absorption vibration }\end{array}\end{array}$ & Functional group & $\begin{array}{c}\text { Biodiesel } \\
\text { Characterization } \\
\text { absorption vibration }\end{array}$ & Functional group \\
\hline 2930.28 & $\begin{array}{c}\text { C-H Aliphatic } \\
\text { stretching } \\
\text { C-H Aliphatic } \\
\text { stretching }\end{array}$ & 3014.44 & C-H Stretching of vinyl \\
\hline 1745.39 & C=O stretching & 2832.39 & C-H Aliphatic \\
& C-H Bending & 1739.96 & $\begin{array}{c}\text { C-H Aldehyde } \\
\text { stretching }\end{array}$ \\
\hline 1451.63 & O-H Bending & 1461.82 & C=0 \\
1363.03 & C-O Stretching & 1175.96 & O-H Bending \\
\hline 1169.82 & & 1104.67 & C-O Stretching \\
\hline
\end{tabular}

with multiple regressions using Design-Expert 12.0 software. Regression analysis yield three linear coefficients $(A, B, C)$, three quadratic coefficients $\left(A^{2}, B^{2}, C^{2}\right)$ and three cross product coefficients $(A B, A C, B C)$ for the full model (Table 4 ). Furthermore, Table 4.3 describes the ANOVA for the response surface quadratic model. The Statistical analysis on factors affecting biodiesel yield, the Design Expert 12.0 program was used in the regression analysis and analysis of variance (ANOVA).

\subsubsection{ACTUAL AND PREDICTED VALUES}

Response Surface Methodology was utilized to evaluate the relations between the response (\% biodiesel yields) and the three reaction variables. Twenty experiments were performed in a randomized order. The results for each point base on the experimental design are shown in Table 4.3. The percentage of biodiesel yield obtained at the design points of different reaction conditions as shown in Table 4 , where the actual or experimental as well as predicted values of percentage yield of biodiesel at the design points are shown in Table 4 . The actual yields of biodiesel produced via different process parameters were calculated and obtained, thus ranged from $23 \%$ to $54 \%$. The yield of the transesterification processes were calculated as the sum of weight of biodiesel produced to weight of oil used multiplied by 100 . It was also observed from Table 4 that the actual values of the biodiesel yield are in agreement with the predicted values as their differences are minimal.

\subsubsection{THE QUADRATIC MODEL}

The multiple regression coefficients were obtained by employing a least square technique to predict quadratic polynomial model for the biodiesel content. Hence, the best fitting model was determined. The model was selected based on the highest order polynomial where the additional terms were significant and the model was not aliased as suggested by the software (seeTable 5 and Table 6 ). The coefficients of the 
Table 4 Relationship between Actual and Predicted Biodiesel Yield

\begin{tabular}{|c|c|c|c|c|c|c|c|c|}
\hline Run Order & $\begin{array}{l}\text { Actua } \\
\text { Value }\end{array}$ & $\begin{array}{l}\text { Predicte } \\
\text { Value }\end{array}$ & Residual & Leverage & $\begin{array}{l}\text { Internally } \\
\text { Studen- } \\
\text { tized } \\
\text { Residu- } \\
\text { als }\end{array}$ & $\begin{array}{l}\text { External } \\
\text { Stu- } \\
\text { den- } \\
\text { tized } \\
\text { Resid- } \\
\text { uals }\end{array}$ & $\begin{array}{l}\text { Cook's } \\
\text { Dis- } \\
\text { tance }\end{array}$ & $\begin{array}{l}\text { Influence } \\
\text { on Fit- } \\
\text { ted } \\
\text { Value } \\
\text { DFFITS }\end{array}$ \\
\hline 1 & 40.50 & 40.91 & -0.4132 & 0.793 & -1.011 & -1.012 & 0.392 & -1.983 \\
\hline 2 & 42.80 & 44.31 & -1.51 & 0.491 & -2.351 & -3.335 & 0.533 & $-3.275^{1}$ \\
\hline 3 & 23.00 & 22.77 & 0.2268 & 0.793 & 0.555 & 0.535 & 0.118 & 1.048 \\
\hline 4 & 54.00 & 52.98 & 1.02 & 0.118 & 1.207 & 1.239 & 0.020 & 0.453 \\
\hline 5 & 52.60 & 52.83 & -0.2273 & 0.491 & -0.355 & -0.338 & 0.012 & -0.332 \\
\hline 6 & 53.00 & 52.35 & 0.6527 & 0.491 & 1.018 & 1.020 & 0.100 & 1.002 \\
\hline 7 & 42.00 & 42.26 & -0.2632 & 0.793 & -0.644 & -0.624 & 0.159 & -1.222 \\
\hline 8 & 52.40 & 52.98 & -0.5818 & 0.118 & -0.690 & -0.670 & 0.006 & -0.245 \\
\hline 9 & 53.30 & 52.98 & 0.3182 & 0.118 & 0.377 & 0.360 & 0.002 & 0.132 \\
\hline 10 & 33.00 & 34.13 & -1.13 & 0.491 & -1.758 & -2.007 & 0.298 & -1.971 \\
\hline 11 & 31.50 & 31.02 & 0.4768 & 0.793 & 1.167 & 1.191 & 0.522 & $2.333^{1}$ \\
\hline 12 & 27.60 & 27.61 & -0.0132 & 0.793 & -0.032 & -0.031 & 0.000 & -0.060 \\
\hline 13 & 54.00 & 52.98 & 1.02 & 0.118 & 1.207 & 1.239 & 0.020 & 0.453 \\
\hline 14 & 52.70 & 52.98 & -0.2818 & 0.118 & -0.334 & -0.319 & 0.001 & -0.117 \\
\hline 15 & 52.80 & 53.43 & -0.6273 & 0.491 & -0.978 & -0.976 & 0.092 & -0.959 \\
\hline 16 & 37.00 & 36.73 & 0.2727 & 0.491 & 0.425 & 0.407 & 0.017 & 0.400 \\
\hline 17 & 31.50 & 30.87 & 0.6268 & 0.793 & 1.534 & 1.664 & 0.903 & $3.259^{1}$ \\
\hline 18 & 23.10 & 22.92 & 0.1768 & 0.793 & 0.433 & 0.414 & 0.072 & 0.812 \\
\hline 19 & 29.00 & 28.96 & 0.0368 & 0.793 & 0.090 & 0.086 & 0.003 & 0.167 \\
\hline 20 & 53.20 & 52.98 & 0.2182 & 0.118 & 0.259 & 0.246 & 0.001 & 0.090 \\
\hline
\end{tabular}

response surface model as provided by the above quadratic model equation was also evaluated. From the ANOVA of response surface quadratic model for biodiesel conversion, the Model F-value of 348.17 and Prob $>$ F of $<0.0001$ implied that the model was significant.

For the model terms, values of P-values less than 0.0500 indicated that model terms were significant. In this case $A, B, A B, A^{2}, B^{2}$ were significant model terms. Values greater than 0.1000 indicated the model terms were not significant. If there are many insignificant model terms (all have Prob> F less than 0.050). This tells us that the catalyst concentration, methanol to oil ratio, and their quadratic terms affect the yield much significantly. However, the interaction terms were found to be insignificant except $A B$ since the values were greater than 0.0500 indicating that the model terms were insignificant (Table 5 ). As we observed from p-values of the model coefficients in Table 4.8, the value of the catalyst concentration and methanol to oil molar ratio in both linear and quadratic model are much less than 0.0001 . This indicated that they are the most significant in determining the model than the rest. However, in order to minimize error, the coefficients were considered in the design. The lack of fit from the ANOVA analysis indicated that the model does indeed represent the actual 
relationships of reaction parameters, which were well within the selected ranges. The Lack of Fit F-value of 2.75 implied that the Lack of Fit is not significant relative to the pure error. There is a $14.57 \%$ chance that a Lack of Fit F-value this large value could occur due to noise. Non-significant lack of fit is good because we want the model to fit.

Table 5 Analysis of Variance (ANOVA) for Response Surface Quadratic Model of Transesterification Process

\begin{tabular}{|cccclll}
\hline Source & Sum of Squares & df & Mean Square & F-value & p-value & \\
\hline Model & 2529.62 & 9 & 281.07 & 348.17 & $<0.0001$ & significant \\
\hline A-Cat.con & 16.90 & 1 & 16.90 & 20.93 & 0.0010 & significant \\
\hline B-Molar ratio & 161.60 & 1 & 161.60 & 200.18 & $<0.0001$ & significant \\
\hline C-Temp & 0.9000 & 1 & 0.9000 & 1.11 & 0.3159 & not significant \\
\hline AB & 228.98 & 1 & 228.98 & 283.64 & $<0.0001$ & significant \\
\hline AC & 0.0000 & 1 & 0.0000 & 0.0000 & 1.0000 & not significant \\
\hline BC & 1.13 & 1 & 1.13 & 1.39 & 0.2651 & not significant \\
\hline$A^{2}$ & 847.45 & 1 & 847.45 & 1049.75 & $<0.0001$ & significant \\
B $^{2}$ & 59.58 & 1 & 59.58 & 73.80 & $<0.0001$ & significant \\
C $^{2}$ & 0.0582 & 1 & 0.0582 & 0.0721 & 0.7938 & not significant \\
\hline Residual & 8.07 & 10 & 0.8073 & & & \\
\hline Lack of Fit & 5.92 & 5 & 1.18 & 2.75 & 0.1457 & not significant \\
\hline Pure Error & 2.15 & 5 & 0.4307 & & & \\
\hline Cor Total & 2537.69 & 19 & & & & \\
\hline
\end{tabular}

\subsubsection{FINAL EQUATION IN TERMS OF CODED FACTORS}

Yield $=+52.98+1.30 * \mathrm{~A}+4.02 * \mathrm{~B}+0.3000 * \mathrm{C}+5.35^{*} \mathrm{~A} * \mathrm{~B}+0.0000 * \mathrm{~A} * \mathrm{C}+0.3750 * \mathrm{~B} * \mathrm{C}-$

\section{$17.55^{*} \mathrm{~A}^{2}-4.65 * \mathrm{~B}^{2}+0.1455^{*} \mathrm{C}^{2}$ Equation (3.1)}

Where, $\mathrm{A}=$ Reaction temperature, $\mathrm{B}=$ Molar ratio of methanol to oil, $\mathrm{C}=$ Catalyst concentration

\subsubsection{COEFFICIENTS IN TERMS OF CODED FACTORS}

The coefficient estimate represents the expected change in response per unit change in factor value when all remaining factors are held constant. The intercept in an orthogonal design is the overall average response of all the runs. The coefficients are adjustments around that average based on the factor settings. When the factors are orthogonal the Variance Inflation Factor (VIFs) are 1; Variance Inflation Factor (VIFs) greater than 1 indicate multi-colinearity, the higher the Variance Inflation Factor, the more severe the correlation of factors. As a rough rule, Variance Inflation Factors less than 10 are tolerable. 


\subsubsection{FINAL EQUATION IN TERMS OF ACTUAL FACTORS}

FAME $\quad$ Yield $=19.43162+15.47309^{*} \mathrm{C}+2.70200 * \mathrm{M}-0.540025^{*} \mathrm{~T}+0.428000^{*} \mathrm{C} * \mathrm{M}-$ 1.35388E-15*C* T-2.80873* $\mathrm{C}^{2}-0.186182 * \mathrm{M}^{2}+0.004040 * \mathrm{~T}^{2}$ Equation (3.2)

Where, $\mathrm{T}=$ Reaction temperature, $\mathrm{M}=$ Molar ratio of methanol to oil, $\mathrm{C}=$ Catalyst concentration

\subsubsection{MODEL ADEQUACY OF QUADRATIC MODEL}

The quality of the model developed was evaluated based on the correlation coefficient value, $R$ square $\left(\mathrm{R}^{2}\right)$. The $\mathrm{R}^{2}$ value for Equation above was 0.9996 . This indicated that $99.96 \%$ of the total variation in the biodiesel yield was attributed to the experimental variables studied. The closer the $\mathrm{R}^{2}$ value to unity, the better the model will be (5), as it will give predicted values, which are closer to the actual values for the response.

\begin{tabular}{cccclll}
\hline Table 6 Regression Coefficients and Significance of Response Surface Quadratic Model \\
\hline Factor & $\begin{array}{c}\text { Coefficient } \\
\text { Estimate }\end{array}$ & df & $\begin{array}{c}\text { Standard } \\
\text { Error }\end{array}$ & $\begin{array}{l}\mathbf{9 5 \%} \text { CI } \\
\text { Low }\end{array}$ & $\begin{array}{l}\mathbf{9 5 \%} \text { CI } \\
\text { High }\end{array}$ & VIF \\
Intercept & 52.98 & 1 & 0.3089 & 52.29 & 53.67 & \\
A-Cat.con & 1.30 & 1 & 0.2841 & 0.6669 & 1.93 & 1.0000 \\
B-Molar & 4.02 & 1 & 0.2841 & 3.39 & 4.65 & 1.0000 \\
ratio & & 1 & 0.2841 & -0.3331 & 0.9331 & 1.0000 \\
C-Temp & 0.3000 & 1 & 0.3177 & 4.64 & 6.06 & 1.0000 \\
AB & 5.35 & 1 & 0.3177 & -0.7078 & 0.7078 & 1.0000 \\
AC & 0.0000 & 1 & 0.3177 & -0.3328 & 1.08 & 1.0000 \\
BC & 0.3750 & 1 & 0.5418 & -18.76 & -16.35 & 1.82 \\
A $^{2}$ & -17.55 & 1 & 0.5418 & -5.86 & -3.45 & 1.82 \\
B $^{2}$ & -4.65 & 1 & 0.5418 & -1.06 & 1.35 & 1.82 \\
C $^{2}$ & 0.1455 & & & & & \\
\hline
\end{tabular}

Table 7 Model Adequacy of Quadratic Model

\begin{tabular}{ccccccc}
\hline Std. Dev. & Mean & C.V. \% & $\mathbf{R}^{2}$ & Adjusted $\mathbf{R}^{2}$ & Predicted $^{2}$ & Adeq Precision \\
0.8985 & 41.95 & 2.14 & 0.9968 & 0.9940 & 0.9831 & 48.2493 \\
\hline
\end{tabular}

The Predicted $\mathrm{R}^{2}$ of 0.9831 is in reasonable agreement with the Adjusted $\mathrm{R}^{2}$ of 0.9940 (Table 4.6); i.e. the difference is less than 0.2.Adeq Precision measures the signal to noise ratio. A ratio greater than 4 is desirable. The ratio of 48.249 indicated an adequate signal. This model can be used to navigate the design space. The value of the adjusted coefficient of determination (Adj $\mathrm{R}^{2}=0.9940$ ) is also high, thus indicating the significance of the model as well as the value of coefficient of variation (CV) is low $(2.14 \%)$, thereby indicating the reliability of the results of the fitted model.

From the ANOVA and regression analysis on Table 4.4 and Table 4.5 respectively, it can be seen that the linear terms $(A, B)$, the quadratic term $\left(A^{2}, B^{2}\right)$ and the cross 
product $A B$, were significant (because Prob> F less than 0.05), but the interactions (cross products) $\mathrm{AC}, \mathrm{BC}$, and $\mathrm{C}$,

$\mathrm{C}^{2}$ were insignificant.

\subsubsection{EFFECT OF INTERACTIVE OPERATING CONDITIONS ON BIODIESEL YIELD}

From Equation (3.2), it was clearly shown that, all the linear terms had positive coefficients except $C$ which is reaction temperature, whereas the quadratic terms and the interaction terms had negative coefficients except $A B$ and $C^{2}$. Therefore, an increase in $\mathrm{CaO}$ catalyst concentration, methanol to oil molar ratio and reaction temperature, to a certain extent could result in a higher percentage of biodiesel. However, a reduction in the percentage of biodiesel could be noticed when using too high CaO catalyst concentration, and methanol to oil molar ratio. Similar pattern was followed when increasing methanol to oil molar ratio. This is due the positive coefficient for the linear parameters ( $\mathrm{AB}$, and $\mathrm{C}$ ) played the main role when the $\mathrm{CaO}$ catalyst concentration and methanol/oil molar ratio were at lower level. While at higher level, the interaction as well as the quadratic terms shows negative significant effect that leads to decrease the yield since the methanol and triglyceride in the oil are immiscible. Addition of catalyst can facilitate the transesterification reaction and rapidly increase the yield (12). However, when the catalyst concentration was too high, the yield of the biodiesel was reduced. Similarly, the increase of the methanol amount, on one side, it will drive the reaction to the right since the reaction is an equilibrium process; on the other hand, excess methanol will help to increase the solubility of glycerol, which favours the backward reaction to the left. Therefore, the yield of biodiesel is decreasing.

\section{CONCLUSIONS}

In this research work, the experiments were conducted using surface response methodology couple with central composite design to examine the optimal reaction condition for the production of biodiesel using crude castor oil. The biodiesel produced contained an ester functional group and showed that castor oil methyl ester can be used as a possible alternative fuel for diesel engines. Based on the forgoing discussion, the conclusions of this study are summarized as follows: Castor oil can be used as a biodiesel raw material with its high oil content and its non-edible characteristics. Of all the variables studied, the interaction between methanol to oil ratio and amount of catalyst had more influence on the yield of fatty acid methyl ester. The ester yield obtained from the transesterification process of crude castor oil ranged from 23 to $54 \%$. The optimum biodiesel yield of $54 \%$ was obtained at a catalyst concentration of $3.5 \mathrm{wt} \%$, methanol to oil molar ratio of $11: 1$ and Reaction temperature of $62^{\circ} \mathrm{C}$ at a reaction time of $1 \mathrm{hr}$ and 300rpm. From the result of the FTIR and GC-MS the methyl ester groups present in the biodiesel produced was determined. 9-Octadecenoic acid-12-hydroxy- methyl ester was identified as the 
most abundant compound in the biodiesel which has all the functional group reveal by the FTIR.

\section{ACKNOWLEDGEMENT}

The research team wishes to acknowledge financial contribution of TETfund and Adamawa State University, Mubi, for the success of this research work.

\section{REFERENCES}

Andrijanto, E. (2012). The study of heterogeneous catalyst for biodiesel synthesis (Unpublished doctoral dissertation). University of Hunddersfield.

Arzamendi, G., Campo, I., Arguiñarena, E., Sánchez, M., Montes, M., \& Gandía, L. M. (2007). Synthesis of biodiesel with heterogeneous $\mathrm{NaOH} /$ alumina catalysts: Comparison with homogeneous NaOH. Chemical Engineering Journal, 134(1-3), 123-130. Retrieved from https://dx.doi.org/10.1016/j.cej.2007.03.049 10.1016/j.cej.2007.03.049

Atapour, M., \& Kariminia, H.-R. (2011). Characterization and transesterification of Iranian bitter almond oil for biodiesel production. Applied Energy, 88(7), 2377-2381. Retrieved from https://dx.doi.org/10.1016/j.apenergy.2011.01.014 10.1016/j.apenergy.2011 01.014

Balat, M., \& Balat, H. (2008). A critical review of bio-diesel as a vehicular fuel. Energy Conversion and Management, 49(10), 2727-2741. Retrieved from https://dx.doi.org/10 .1016/j.enconman.2008.03.016 10.1016/j.enconman.2008.03.016

Chew, T. L., \& Bhatia, S. (2008). Catalytic processes towards the production of biofuels in a palm oil and oil palm biomass-based biorefinery. Bioresource Technology, 99(17), 7911-7922. Retrieved from https://dx.doi.org/10.1016/j.biortech.2008.03.009 10 .1016/j.biortech.2008.03.009

Chukwueyem, S. R., Adeniyi, O. A., Williams, J. K., Magnus, O. A., Peter, D. G., \& Margaret, J. H. (2015). Analysis of energy market conditions in Nigeria. In Analysis of energy market conditions in Nigeria. Abuja.

Chung, K. H., Chang, D. R., \& Park, B. G. (2008). Removal of free fatty acidin waste frying oil by esterification with methanol on zeolite catalysts. Bioresource Technology, 99(16), $7438-7448$.

Demirbas, A. (2008). Biodiesel a realistic fuel for diesel engines. Biodiesel a realistic fuel for diesel engines, 1-108.

Farahmandjou, M., \& Golabiyan, N. (2016). Synthesis and characterization of Alumina (Al203) nanoparticles prepared by simple sol-gel method. Int. J. Bio-Inorg. Hybr. Nanomater, 5(1), 73-77.

Freedman, B., Pryde, E. H., \& Mounts, T. L. (1984). Variables affecting the yields of fatty esters from transesterified vegetable oils. Journal of the American Oil Chemists Society, 61(10), 1638-1643. Retrieved from https://dx.doi.org/10.1007/bf02541649 10 $.1007 / \mathrm{bf0} 02541649$

Fukuda, H., Kondo, A., \& Noda, H. (2001). Biodiesel fuel production by transesterification oils. Journal of Bioscience and Bioengineering, 92(5), 405-416.

Gomes, M. C., Pereira, N. C., \& Barros, S. T. (2010). Separation of biodiesel and glycerol using ceramic membrane. Journal of Membrane Science, 352(1-2), 271-276.

Gui, M. M., Lee, K. T., \& Bhatia, S. (2008). Feasibility of edible oil vs. non-edible oil vs. waste 
edible oil as biodiesel feedstock. Energy, 33(11), 1646-1653. Retrieved from https:// dx.doi.org/10.1016/j.energy.2008.06.002 10.1016/j.energy.2008.06.002

Musa, I. A. (2016). The effects of alcohol to oil molar ratios and the type of alcohol on biodiesel production using transesterification process. Egyptian Journal of Petroleum, 25(1), 21-31. Retrieved from https://dx.doi.org/10.1016/j.ejpe.2015.06.007 10.1016/j.ejpe .2015 .06 .007

Nahadi, J. J., \& IM, A. (2018). The Effects of Variation of Catalyst Concentration on Biodiesel Production. International Journal of Research -Granthaalayah, 6(9), 487-496.

Zavarize, D. G., Braun, H., \& de Oliveira, J. D. (2021). Methanolysis of low-FFA waste cooking oil with novel carbon-based heterogeneous acid catalyst derived from Amazon açaí berry seeds. Renewable Energy, 171, 621-634. Retrieved from https://dx.doi.org/10.1016/ j.renene.2021.02.112 10.1016/j.renene.2021.02.112 